\title{
154/34,5 kV Güç Transformatörleri için Diferansiyel Koruma Rölesi Koordinasyonu Benzetimi
}

\author{
Ozan AKDAĞ ${ }^{* 1}$, Deniz PEKÖZ ${ }^{1}$, Celaleddin YEROĞLU² \\ ${ }^{1}$ Türkiye Elektrik İletim AŞ, Malatya \\ 2İnönü Üniversitesi, Mühendislik Fakültesi, Bilgisayar Mühendisliği Bölümü, Malatya
}

(Alınış / Received: 11.10.2017, Kabul / Accepted: 15.02.2018, Online Yayınlanma / Published Online: 27.03.2018)

\author{
Anahtar Kelimeler \\ Güç sistemleri analizi, \\ Diferansiyel koruma rölesi, \\ Sanal model, \\ Benzetim, \\ Koruma koordinasyonu
}

Özet: Güç transformatörleri, güç sistemlerinde gerilimin seviyesini değiștirmede kullanılır. Güç transformatörleri üretim santrallerindeki elektrik enerjisinin gerilim seviyesini yükselterek iletim sistemine aktarır. Türkiye'de iletim gerilimi genelde $380 \mathrm{kV} / 154$ kV' dur. Bu seviyedeki gerilim, indirici merkezlerinde yaklaşık $34,5 \mathrm{kV}$ gerilim seviyesine düşürülür. Güç transformatörleri güç sistemindeki teçhizatlar içinde en pahalı ve en önemlilerinden biridir. Bu yüzden güç transformatörlerini, güç sistemindeki çeşitli arıza durumlarından ya da kendi içinde oluşan arızalardan korumak önemlidir. Bu işlem çeşitli koruma röleleri ile sağlanırken, genelde diferansiyel koruma röleleri kullanılır. Bu çalışmada temel özelliklere sahip bir koruma rölesinin benzetimi yapılarak, 154/34,5 kV bir güç transformatörünün koruma koordinasyonu analizi yapılmıştır. Güç sisteminin modellenmesi ve temel diferansiyel koruma rölesi benzetimde DigSilent güç sistemleri analiz programı kullanılmıştır.

\section{Coordination Simulation of Differential Protection Relay for 154/34,5 kV Power Transformers}

\section{Keywords}

Analysis of power systems, Differential protection relay, Virtual model,

Simulation,

Protection coordination

\begin{abstract}
Power transformers are used to change the level of voltage in power systems. Power transformers increase the voltage level of electrical energy in production plants and transfer them to the transmission system. The transmission voltage in Turkey is generally $380 / 154 \mathrm{kV}$. The voltage at this level is reduced to a voltage of about $34.5 \mathrm{kV}$ at the power down-center. Power transformers are the most expensive and important equipment among the power system. Therefore it is important to protect the power transformers from various malfunctions in the power system or from faults occurring in it. While this process is accomplished with various protection relays, the differential protection relays are usually used. In this study, the protection coordination relay analysis of a power transformer of $154 / 34.5 \mathrm{kV}$ was done by modelling a protection relay with basic characteristics. The DigSilent power systems analysis software was used to model the power system and simulate the basic differential protection relay.
\end{abstract}

\section{Giriş}

Elektrik enerjisi üretim, iletim ve dağıtım safhalarından geçerek tüketicilere ulaşır. Elektik enerjisinin bu geçiş safhalarındaki en önemli problemi, sürekliliğidir. Enerjinin sürekliliği, beraberinde koruma koordinasyonu konusunu getirir. Koruma koordinasyonu ile güç sisteminin bütününde güvenli bir şekilde yük (güç) akışı sağlanır. İyi bir koruma koordinasyonu ile güç sisteminin herhangi bir bölümünde arıza veya önceden öngörülmüş şartların dışına çıkan bir durum oluşması halinde bu bölüm (arızalı bölüm) güç sisteminden izole edilerek güç akışının devamlılığı sağlanır. Bu yüzden seçici bir koruma koordinasyonu sağlamak oldukça önemlidir. Güç sistemlerinde koruma koordinasyonu, koruma röleleri ile sağlanır.

Koruma röleleri özelliğine göre akım, gerilim, empedans bilgilerini alarak bağlı olduğu kesiciye açma/kapama sinyalleri yollayarak koruma işlemini yapar. Güç sistemlerinde güç transformatörlerinin korunması genelde aşırı akım röleleri ile birlikte diferansiyel koruma röleleri ile yapılır. Güç 
transformatörleri harici ve dâhili birçok arıza tipine maruz kalmaktadır [1, 2]. Dâhili arızalar, güç transformatörünün içyapısından kaynaklanan arızalar olduğu için daha önemlidir. Dâhili arızalardan güç transformatörlerinin korunması, diferansiyel koruma röleleri ile sağlanır. Güç sistemleri karmaşık bir görünümde olduğundan, güç sistemlerinde analizler yapmak oldukça zordur. Bu zorluğun üstesinden gelmek için mevcut güç sisteminin modelini oluşturup, benzetimini yapmak önemlidir [3]. Böylece güç sistemi hakkında önemli bilgiler, önceden öngörülebilir. Son yıllarda birçok özel yazılım paketleri, güç sistemlerinin sanal ortamda modellerinin oluşturulmasına imkân sağlamaktadır. $\mathrm{Bu}$ modeller ile koruma koordinasyonu benzetimi yapılarak, en iyi koruma koordinasyonu ayarlarının yapılması sağlanabilir. Bu tarz güç sistemi modelleme programları ile yapılan bazı koruma koordinasyonu çalışmaları şöyle özetlenebilir.

Guzman ve arkadaşları, bir güç transformatörünün diferansiyel korumasına yönelik yeni bir yaklaşım sunmuşlardır. Bu yaklaşım ile harmonik kısıtlama ve bloke etme özelliklerini yeni bir dalga şekli tanıma tekniği ile birleștirmişlerdir [2]. Rafa, PSCAD programı sayesinde bir güç transformatörünün diferansiyel röle ile korunmasını modelleyerek anlatmıştır [1]. Serrican, Petkim Petrokimya Aliağa Tesisinin elektrik sisteminin yük akışı ve kısa devre hesapları konusunda tez çalışması yapmıştır [3]. Türen, hall etkili dönüștürücü kullanan diferansiyel rölenin bir güç transformatöründe kullanılmasını Matlab programı yardımı ile modelleyerek yapmıștır [4]. Perdahçı ve Can, büyük bir tesisin röle koordinasyonu benzetimini PSS-SINCAL programı ile yapıp analiz etmişlerdir [5]. Gençaydın, 154 kV İstanbul güç sisteminin bir kısmını PSS-SINCAL programı ile modelleyip mesafe röle koordinasyonu yapmıştır [6]. Nuroğlu, dağıtım üretim içeren dağıtım şebekelerinde DigSilent programı ile merkezi röle koordinasyonu tasarımı yapmıştır [7]. Muangchareon ve arkadaşları, DigSilent programı yardımı ile bir güç sistemine eklenen dağıtılmış üretim sisteminin koruma koordinasyonuna etkisini incelemişlerdir [8]. Kezunoviç ve arkadaşları, bir dijital diferansiyel koruma rölesinin performansını değerlendirmiştir. Diferansiyel koruma rölesinin benzetimini EMTP/ATP programı kullanarak yapmışlardır [9]. Phadko ve Thorp yaptıkları çalışmada 3 fazlı güç transformatörlerinin bilgisayar destekli korunması konusunu ele almışlardır. Bu çalışmada akı ve akım ilişkisini hesaplayan bir diferansiyel koruma tekniği geliştirmişlerdir [10]. Aktaibi ve Rahman yaptıkları çalışmada güç transformatörlerinde diferansiyel koruma rölesi ile koruma yapan bir model geliştirmişlerdir. Güç sistemi modeli ve diferansiyel koruma rölesi tasarımında Matlab-Simulink programı kullanmışlardır [11]. Kara ve arkadaşları yaptıkları çalışmada 12 baralık bir güç sisteminde bulunan güç transformatörlerinin diferansiyel koruma rölesi ile korunmasının benzetimini yapmıșlardır. Benzetim çalıșmasında Matlab-Simulink programı kullanmışlardır [12].

Bu yayında, DigSilent V.15.1.6 güç sistemleri analiz programı yardımı ile 154/34,5 $\mathrm{kV}$ bir güç transformatörünün diferansiyel koruma röle koordinasyonu çalışması yapılmıștır. DigSilent programı, güç sistemlerinin analizi için kullanılan ve aynı zamanda güç sistemlerinde planlanma, optimizasyon gibi ișlemleri gerçekleștirmek için geliştirilen bir yazılımdır. Bu program farklı analizler için (yük akış analizi, koruma koordinasyon analizi vb.) başka bir modülün yüklenmesine veya verilerin yenilenip transfer edilmesine ihtiyaç duymadan çalışır. DigSilent programının temel özellikleri kısaca aşağıda sıralanmıştır;

1. Güç sisteminin modellenmesi, çıktı ve sonuçların alınması,

2. Verilerin işlenerek tek hat diyagramında yapılandirılması,

3. Güç sistemi teçhizatlarının temel veri tabanlarının oluşturulması,

4. Güç sistem planlamasının yapılarak, gerekli öngörülerin önceden değerlendirilmesi,

5. Güç sistemlerinde yük akış analizi, harmonik analiz, flicker analizi, koruma koordinasyonu analizi, kısa devre analizi vb. gibi güç sistemleri analizlerini gerçekleştirmesi.

\section{Diferansiyel Koruma Rölesinin Teorik Altyapısı}

Bu bölümde diferansiyel korumanın temel ilkeleri ve bir diferansiyel koruma rölesinin yapısı ve çalışma mantı̆̆ı anlatılmıştır.

\subsection{Diferansiyel koruma rölesi}

Güç transformatörlerinde diferansiyel koruma rölesi ile güç transformatörünün primer ve sekonder akım trafoları arasındaki alan korunur. $\mathrm{Bu}$ yönü ile diferansiyel koruma röleleri, sınırları önceden belirli bir alanda koruma yapar. Bu alanların dıșında röle devreye girmez. Diferansiyel koruma, akım kıyaslama (vektörel olarak) ilkesiyle akım ölçümü prensibine dayalı bir korumadır. Diferansiyel koruma rölesi ile güç transformatörünün 2 tarafındaki akım değerleri karşılaştırılır. Normal işletme koşullarında röleye giren akım değerinin, diğer tarafından aynı şekilde çıkması istenir. Yani röleye giren çıkan akım değerlerinin eșit ve aralarında $180^{\circ} \mathrm{faz}$ farkı olması istenir. $\mathrm{Bu}$ durum asıl akım trafoları ile ya da gerektiğinde yardımcı akım trafoları ile sağlanır [1315]. Şekil 1'de temel bir diferansiyel koruma rölesinin prensip şeması görülmektedir.

Şekil 1 incelendiğinde normal çalıșma șartlarında, güç transformatörünün her iki yanından aynı akım değerinin geçmesi gerekir. $\mathrm{Bu}$ akım, bir akım trafosundan (AT1) girip, bir diğer akım trafosundan 


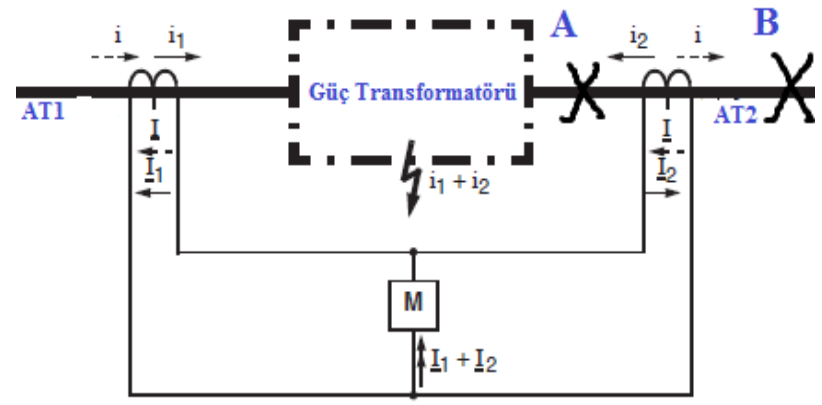

Şekil 1. Diferansiyel koruma rölesinin prensip şeması ve A noktasındaki arızaya tepkisi [15]

(AT2) çıkar. Şayet akım trafosu oranları aynı kabul edilirse, güç transformatörünün AT1 ve AT2 akım trafolarının sekonder sargıları, bir kapalı devre oluşturacak şekilde bağlanır. Bu şekilde yapılan bağlantı ile normal işletme koşulunda M noktasından akım geçmez [14].

Şekil 1'de akım trafoları ile sınırları belirlenen A noktasında bir arıza meydana gelirse, ölçme elemanına her iki taraftan içeri doğru akan $i_{1}+i_{2}$ arıza akımları ile orantılı $\mathrm{I}_{1}+\mathrm{I}_{2}$ akımı ölçme noktasını (M'yi) besler. Sonuç olarak, A noktasında bir arıza meydana geldiğinde M'nin üzerinden geçen akım, önceden ayarlanan akım değerinin (arıza başlatma akım değeri) üzerinde ise diferansiyel röle açma işlemini gerçekleştirir.

Şekil 2'de görüldüğü gibi B noktasında bir arıza meydana gelirse (her iki taraftaki akım trafosunun oranları ve diğer özellikleri aynı kabul edilirse IA=IB), arıza akımı B noktasına doğru akar. B noktasında arıza olduğu an arıza akımları I'A ve I'B olsun. Bu arıza akımları normal zamanda akan akım değerinden c kat fazla olduğu kabul edilirse Denklem 1 ve 2'de görüldügü gibi olur [4].

$$
\begin{aligned}
& I^{\prime} A=c . I A \\
& I^{\prime} B=\text { c. } I B
\end{aligned}
$$

$\mathrm{Bu}$ iki akım değeri akım trafo oranları ve diğer özellikleri aynı olduğu için ölçüm noktasındaki akım değerleri denklem 3 ve 4'de görüldüğü gibi olur.

$$
\begin{aligned}
& i^{\prime} a=c . \quad i a \\
& i^{\prime} b=c . \quad i b
\end{aligned}
$$

$\mathrm{Bu}$ durumda ölçüm noktası M'den akan arıza akımı denklem 5'de görüldüğü gibi sıfır olur. Böylece diferansiyel röle devreye girmez [4].

$$
\text { If }=i^{\prime} b-i^{\prime} a=0
$$

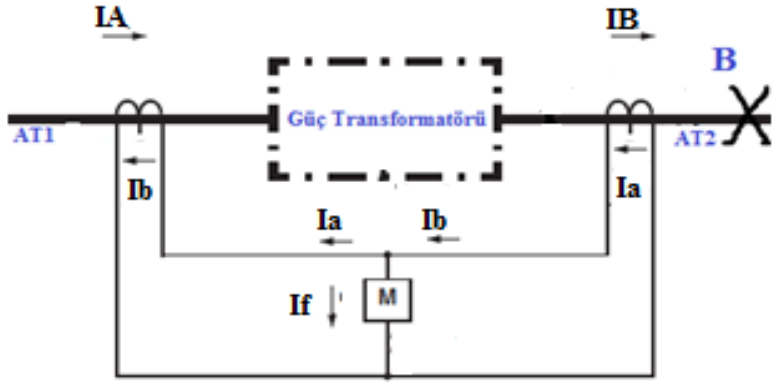

Şekil 2. Diferansiyel koruma rölesinin prensip şeması ve B noktasındaki arızaya tepkisi [15]

Eski tip diferansiyel koruma rölelerinde güç transformatörünün giriş ve çıkıșındaki akım trafo oranlarının farklı olduğu durumda, asıl akım trafoları ile ölçüm noktası arasına dengeleyici akım trafoları konulurdu. Ama günümüzdeki dijital diferansiyel rölelerde sadece güç transformatörünün giriş ve çıkışındaki akım trafo oranlarını girmek yeterlidir. Diferansiyel röle akım trafo oranlarındaki dönüşüm işlemini kendisi yapmaktadır.

\subsection{Diferansiyel rölede akım tutuculuğu}

Akım tutuculuğu, güç transformatörlerinde oluşacak akım değişimlerini, akım trafosu üreticilerinin yaptığı oran hatalarını ya da akım trafolarında mıknatıslanmadan oluşacak akım bozulmalarının etkilerini etkisiz hale getirecek diferansiyel rölelere eklenmiş bir özelliktir.

Güç transformatörlerinde diferansiyel korumada diferansiyel fark akımı genelde güç transformatörlerine giren/çıkan akımın mutlak değer içinde toplamı olarak $|I 1+I 2|$ ya da $\left|I_{1}-I_{2}\right|$ farklı olarak verilir. Bu çalışmada diferansiyel fark IDif, $|I 1+I 2|$ seçilmiştir. Tutuculuk akımı ITut , diferansiyel fark akımına karşı koyucu etki gösteren hatalı açmaları engelleyen akım değeri, bu çalıșmada $|I 1|+|I 2|$ olarak seçilmiştir. Bu iki akım değerinin aralarındaki ilişkiyi anlayabilmek için bir güç transformatöründe dâhili ve harici arıza ișletme koşulu incelenmelidir [15].

Dâhili arıza, güç transformatöründe (Şekil 3) her iki uçtan eşit akımların geçtiği arıza durumu olarak kabul edilirse, $\mathrm{Bu}$ durumda $\mathrm{I}_{2}=\mathrm{I}_{1}$ ve sonuç olarak $|I 1+I 2|$ 'dir. Bu durum denklem 6 ve 7'de görüldüğü gibidir.

$$
\begin{gathered}
\text { IDif }=|I 1+I 2|=|I 1+I 1|=2 .|I 1| \\
\text { ITut }=|I 1|+|I 1|=|I 1|+|I 1|=2 .|I 1|
\end{gathered}
$$

Açma etkisi (IDif) ve tutuculuk (ITut) büyüklükleri birbirine eșit ve toplam arıza akımına karşılık geldiği görülmektedir. 


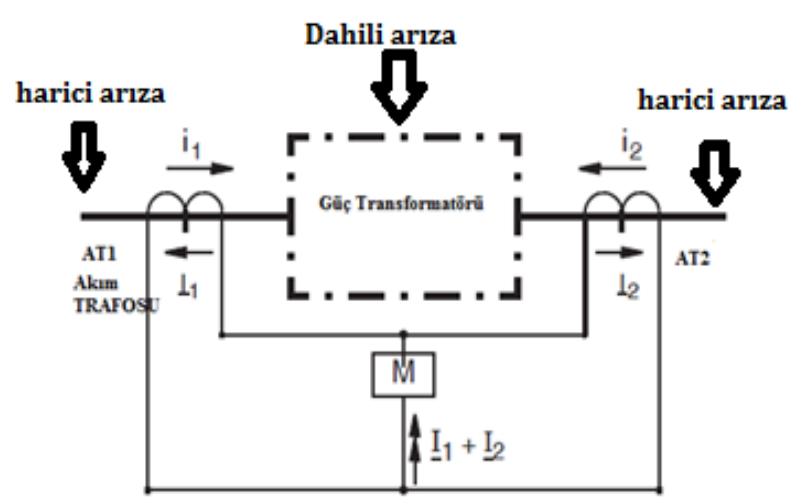

Şekil 3. Akım yönlerinin gösterilmesi [15]

Harici arızada, güç transformatörünün Şekil 3'de üzerinden geçen akım $\mathrm{I}_{2}$ 'nin yönü değiştirilir, böylece bu akımın işareti de değişir. Yani $\mathrm{I}_{2}=-\mathrm{I}_{1}$ olur sonuç olarak; $\left|I_{2}\right|=\left|I_{1}\right|$ 'dir. Bu durum denklem 8 ve 9'da gösterildiği gibidir. $\mathrm{I}_{2}$ akımının yönü değiştiğinden güç transformatörünün üzerinden akım geçmez.

$$
\begin{gathered}
\text { IDif }=|I 1+I 2|=|I 1-I 1|=0 \\
\text { ITut }=|I 1|+|I 1|=|I 1|+|I 1|=2 .|I 1|
\end{gathered}
$$

Bu durumda diferansiyel röle açma yapmaz (IDif = 0 ); (çünkü diferansiyel koruma rölesi iki akım trafosu arasında koruma yapar). Tutuculuk akımı ise güç transformatörünün üzerinden geçen akımın 2 katı olur. Bu arıza durumu diferansiyel koruma rölesinin koruma bölgesine girmez. Bu durumda trafonun primer veya sekonder tarafında bulunan aşırı akım röleleri devreye girerek, harici arızanın olduğu noktadaki güç transformatörünün ilgili kısmını açma işlemi yapar. Örneğin Şekil 3'de görüldüğü gibi sekonder tarafında bir harici arıza oluşması durumunda sadece güç transformatörünün sekonder tarafından beslenen tüketiciler enerjisiz kalır, ama güç transformatörü devreden çıkmaz.

Şekil 4'de bir diferansiyel röleye ait IDif, ITut akımları ile oluşturulan çalışma karakteristiği görülmektedir.

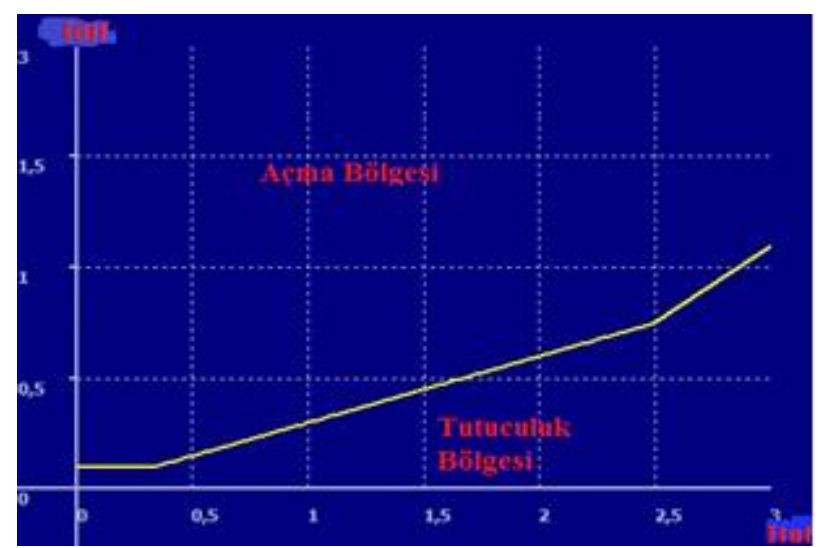

Şekil 4. Diferansiyel korumanın çalışma karakteristiği

\section{Diferansiyel Röle Benzetimi ve Koruma Koordinasyonu}

$\mathrm{Bu}$ bölümde $154 \mathrm{kV}$ iletim sistemi ve bir güç transformatörü modellenecektir. Daha sonra bu model yardımı ile güç transformatöründe koruma yapacak diferansiyel koruma rölesinin nasıl benzetimi yapılıp ayarlandığı anlatılacaktır.

$\mathrm{Bu}$ model yardımı ile sanal arıza senaryoları oluşturularak diferansiyel rölenin bu arızalara tepkileri analiz edilecektir.

\subsection{Diferansiyel koruma rölesinin benzetimi}

Bu çalışmada DigSilent programında Türkiye iletim sistemindeki güç transformatörlerinde koruma yapan diferansiyel koruma rölelerinde kullanılan ayarlara göre diferansiyel koruma rölesinin genel yapısı, karakteristik özellikleri tasarlanarak, modellemesi yapılan güç sisteminde analiz edilmiştir. İlk olarak diferansiyel koruma rölesinin her bir ünitesi oluşturulup, giriş çıkış sinyallerinin ataması yapılmıştır. Şekil 5'de seçilen üniteler görülmektedir. Örneğin Şekil 5'de güç transformatörünün primer ve sekonder kısmında bulunan akım trafoları için diferansiyel koruma rölesine iki adet akım trafolarından gelen akım bilgilerinin olduğu giriş tanımlanmıștır. Bu girişler akım tr1 ve akım tr2 olarak Şekil 5'de görülmektedir. Diğer üniteler de aynı mantık ile seçilmiştir. Daha sonra her bir ünitenin sınır aralıkları belirlenerek ayar değerleri girilmiștir. Şekil 6'da Diferansiyel ünitesinin karakteristik ayarları gösterilmiştir. Şekil 6'da bu ünitenin sınır aralığı ve bu üniteye girilen ayar değeri görülmektedir. Diğer üniteler içinde sınır aralık değerleri ve ayarları aynı şekilde standart ayarlara (Bölüm 3.2'de verilen ayarlara uygun) göre girilmiștir. Daha sonra tüm bu atamalar ve ayarlamalar doğrultusunda diferansiyel koruma rölesinin modellemesi yapılmıştır. Şekil 7'de diferansiyel koruma rölesinin oluşturulan modeli görülmektedir.

Şekil 7'de verilen modelde diferansiyel koruma rölesi için bir haberleşme arayüzü geliştirerek, veriler dinamik bir șekilde, online SCADA erișimine açlabilir. DigSilent programı, statik ve dinamik olarak, online SCADA erişimine olanak sağlamaktadır.

\subsection{Diferansiyel koruma rölesinin ayarlanması}

Bu çalıșmada 154/34,5 kV 50 MVA gücünde bir güç transformatörü için diferansiyel koruma yapacak rölenin ayarları anlatılmıştır. Ülkemiz iletim sistemi standartlarına göre bu ayarlar TEİAŞ tarafından aşağıda görüldüğ̈u gibi belirlenip standartlaştırılmıştır[16]. 


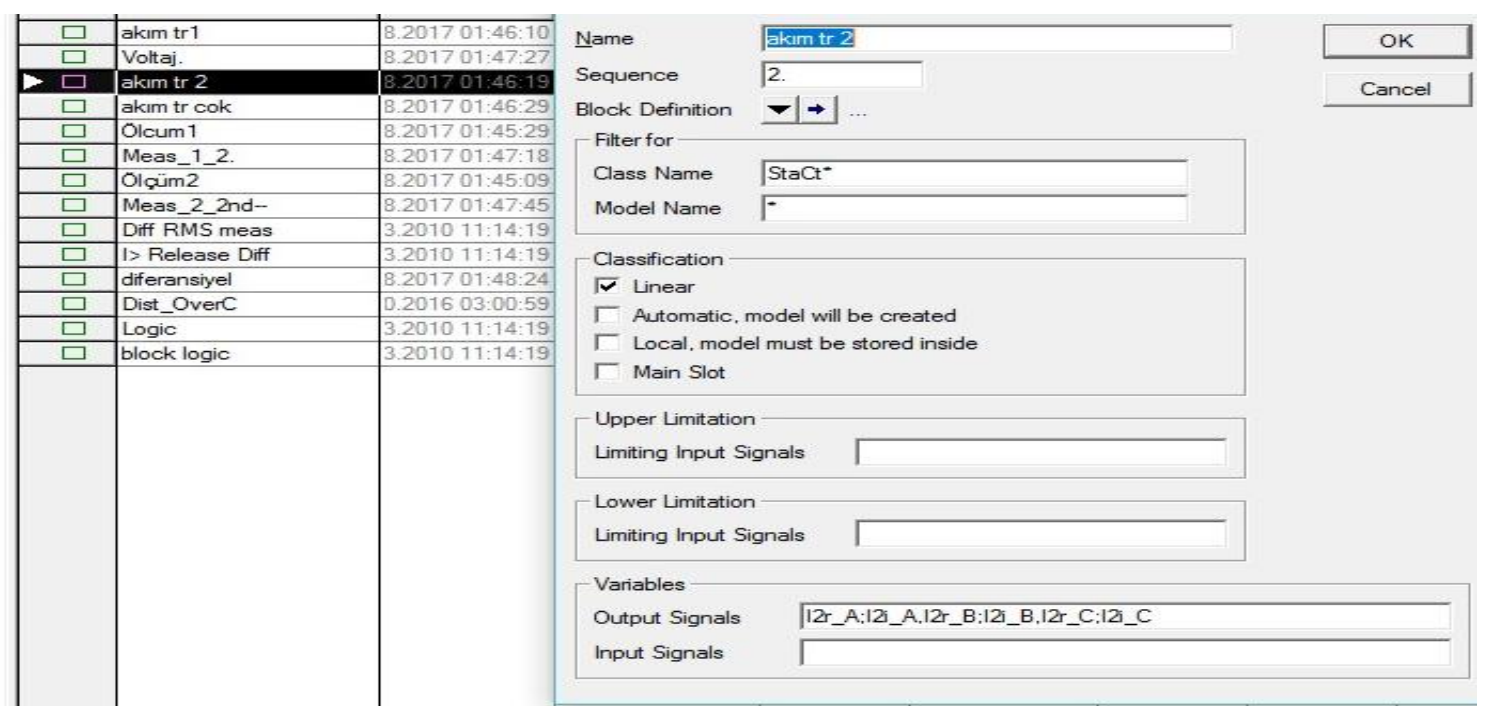

Şekil 5. Diferansiyel koruma rölesinin ünitelerinin oluşturulması

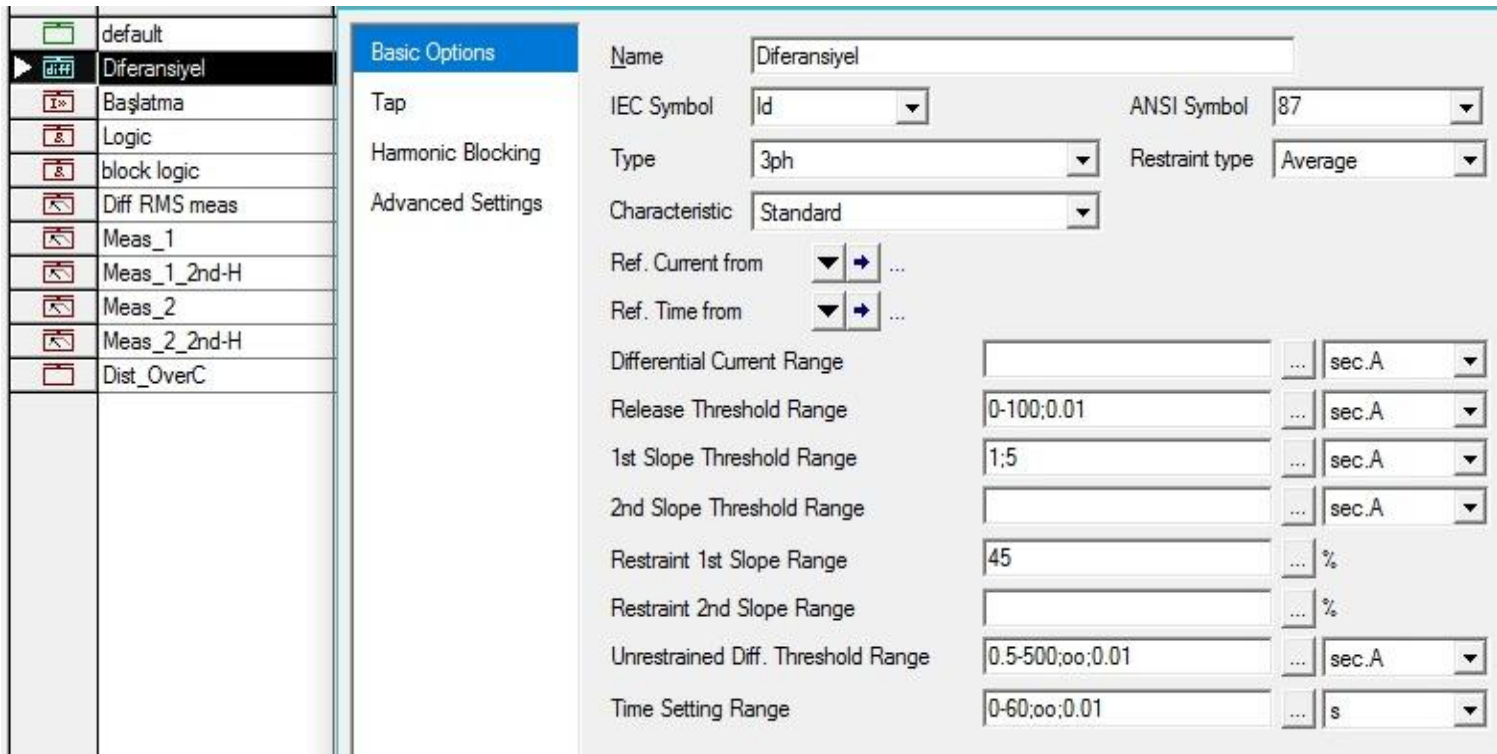

Şekil 6. Diferansiyel koruma rölesinin ünitelerinin karakteristik ayarları

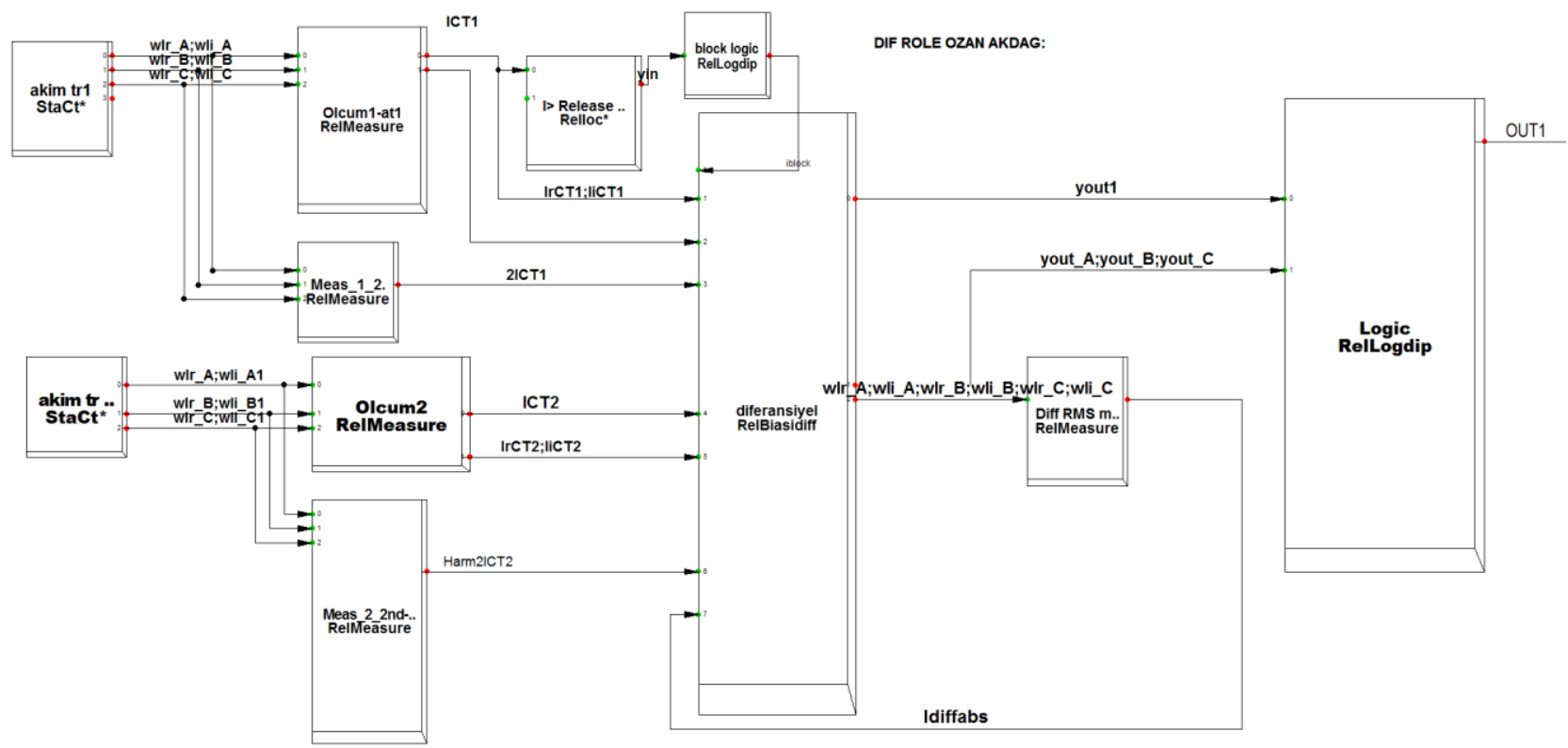

Şekil 7. Diferansiyel koruma rölesinin modeli 
Bu ayarlar,

$$
\begin{aligned}
& \text { IDif >: } 0.2 p u \\
& \text { IDif 》: } 7.5 p u(\text { ani }) \\
& \text { Slope } 1 \text { ĕgri : \%15 - \%25(ITUT } \\
& =I 1+I 2 \text { kabul edilen röleler } i c ̧ i n) \\
& \text { Slope } 2 \text { ĕgri : \%35 - \%50(ITUT } \\
& =I 1+I 2 \text { kabul edilen röleler } i c ̧ i n)
\end{aligned}
$$

$\mathrm{Bu}$ ayarlardan IDif > temel mantığını bu çalışmada tasarlanan güç transformatörü modelinde ele alınarak açıklanırsa, diferansiyel korumadaki fark akımının temel mantığı ortaya konulur.

Şekil 8'de DigSilent ile modellemesi yapılan güç sisteminin tek hat şeması görülmektedir. Modellemede 50 MVA bir güç transformatörünün modellemesi yapılmıştır. Güç transformatörünün primer kısmındaki akım trafosu oranı 200/5 seçilmişken, sekonder tarafında 1000/5 akım trafo oranı seçilmiştir. Bu modelde tasarlanan diferansiyel rölenin ayarlarının röleye girilmesi ise şekil 9'da gösterildiği gibidir.

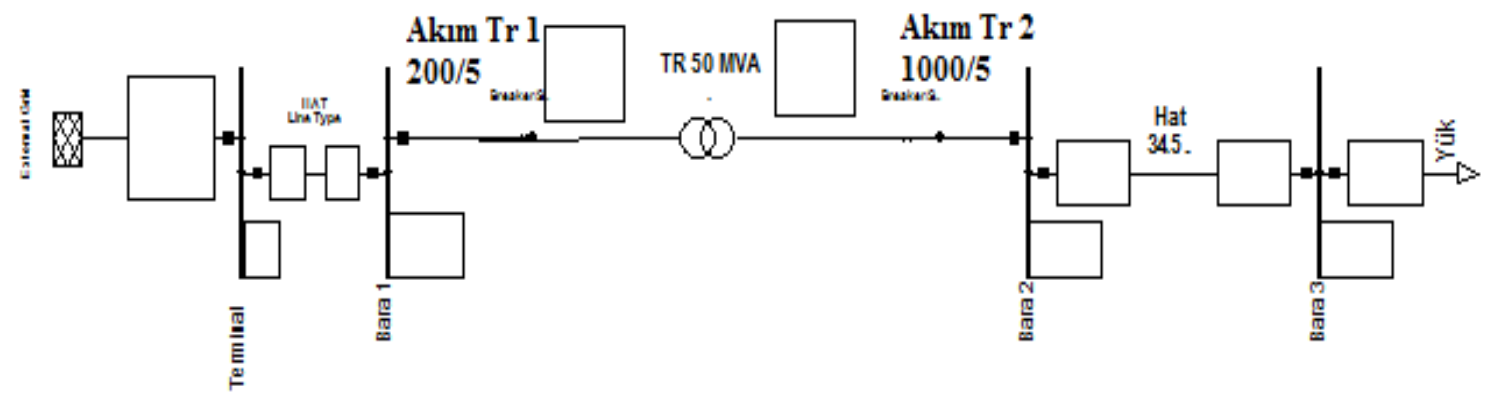

Şekil 8. Güç sisteminin tek hat şeması

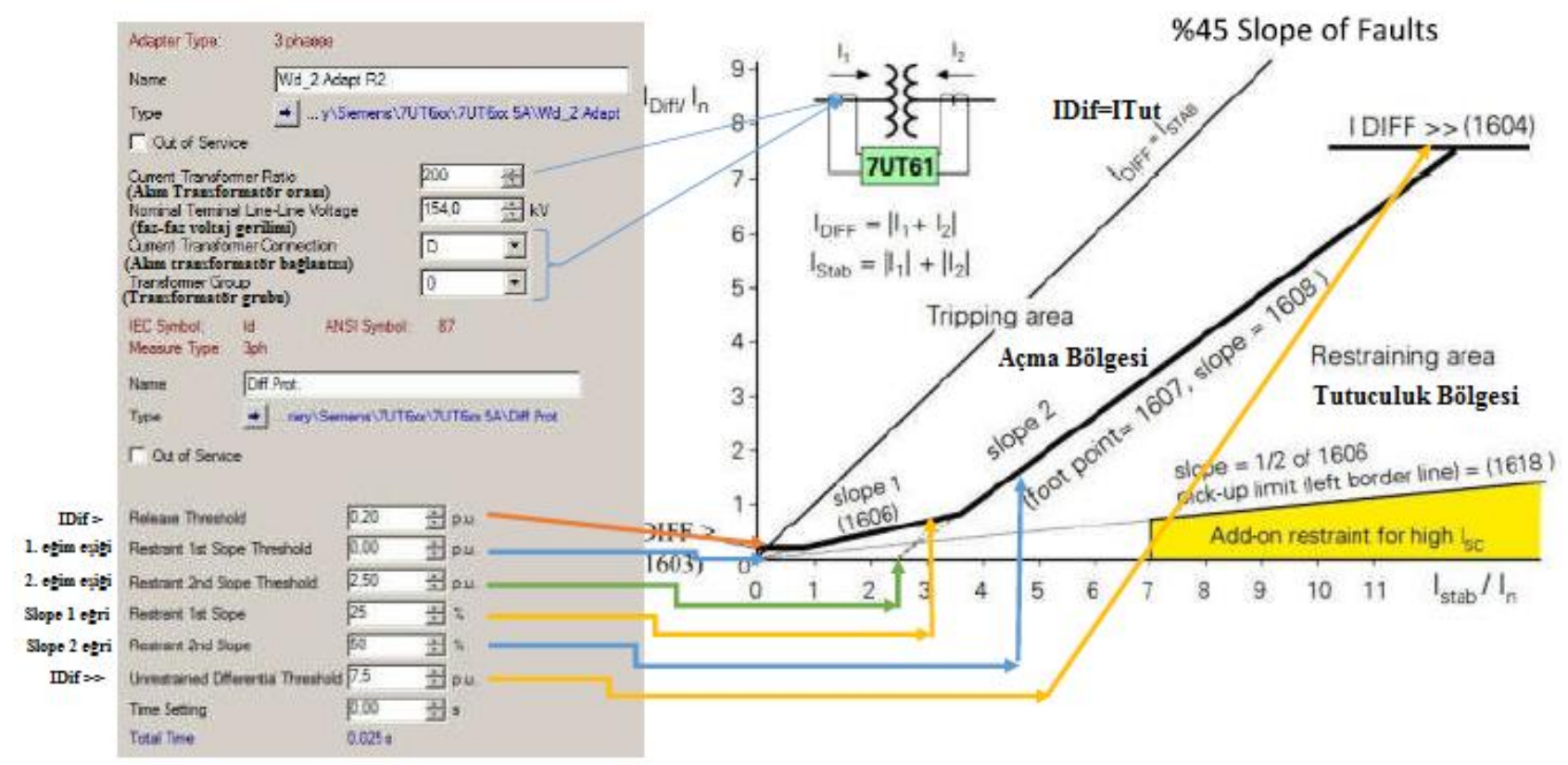

Şekil 9. DigSilent programında diferansiyel rölesine ayarların girildiği ara yüz [16]

Şekil 9'da IDif $>0,2 p u$ seçilmiştir. Bunun anlamı güç transformatörünün gücünün 0,2 ile çarpılması ile ortaya çıkan değerde güç transformatörünün diferansiyel koruma yapacağını gösterir (50MVA $\mathrm{x}$ IDif $>=10 \mathrm{MVA}$ ] [12]. Bu değer güç transformatörünün primer ve sekonder kısmındaki fark gücünün en fazla 10 MVA olacağını gösterir. Bu fark gücü üzerinden akım değerleri hesaplanır ve bu akım değerleri bizim için IDif $>$ değerleri kabul edilir. Bu akım değeri ise aşağıdaki bağıntılara göre bulunur.

$$
\begin{aligned}
& S \text { dif }=\sqrt{3} x U_{154 k V} x I_{\text {dif } 154 k V} \\
& S d i f=\sqrt{3} x U_{34,5 k V} x I_{\text {dif } 34,5 k V}
\end{aligned}
$$

Burada, S: Güç trafosunun fark gücü, $U_{154 / 33,6 k V}$ : Nominal gerilim

Eşitlik 14 ve 15 de Idif değerleri sırasıyla 37,4 A, 175,16 A bulunmuștur. 175,16 A değeri Şekil 10'da 
görüldüğü gibi Idif başlatma akım değeridir. Daha sonra bu değerler akım trafosu oranları dâhilince eşitlik 16 ve 17 ile küçültülerek diferansiyel röleye gönderilir.

$$
\begin{gathered}
\text { Primer } I_{d i f 154 k V}=\frac{37.4 \mathrm{~A}}{\frac{200}{5}}=0.93 \\
\text { Sekonder } I_{\text {dif } 34,5 k V}=\frac{175.16 \mathrm{~A}}{\frac{1000}{5}}=0.87
\end{gathered}
$$

Primer tarafinda 0,93 A ve üzerinde, sekonder tarafında ise 0,87 A ve üzerinde diferansiyel röle açma sinyali üretecektir. Örneğin güç transformatörünün primer tarafından 45 MVA bir güç geçerken sekonder tarafindan 20 MVA güç geçtiği esnada fark gücü 25 MVA olacaktır. Bu değer eşitlik 15-17'de yerine koyulursa 0,93 A ve 0,87 A değerlerinden büyük bir akım değeri hesaplanacaktır ve böylece diferansiyel röle devreye girerek açma sinyali üretecektir. IDif $\gg$ ayarı, ani ayarıdır. Bu değer 7.5 -8 pu olarak seçilir. Hesaplanması IDif > ayarlanma mantığı ile aynıdır. Slope 1 ayarı ve Slope 2 ayarı ise bölüm 3.2'de verilen aralıklarda seçilir. Slope 1 IDif $>$ ile Itut akımı arasındaki eğim değeridir. Slope 2 ise IDif $\gg$ ile Itut arasındaki eğimi gösterir. Bu durum Şekil 9'da görüldüğü gibidir. Şekil 9'da verilen açma eğrisi bu eğimlere göre çizilir. Bu çalıșmada slope 1 açısı 25 seçilmişken, slope 2 açısı 50 seçilmiştir.

\subsection{Diferansiyel koruma koordinasyonu}

Bölüm 3.2' de verilen diferansiyel koruma ayar değerleri modellemesi yapılmış güç sistemindeki güç transformatörünü koruyan diferansiyel koruma rölesinin ayar kısmına girilir. Daha sonra güç sistemi modelinde arıza senaryoları olușturularak,

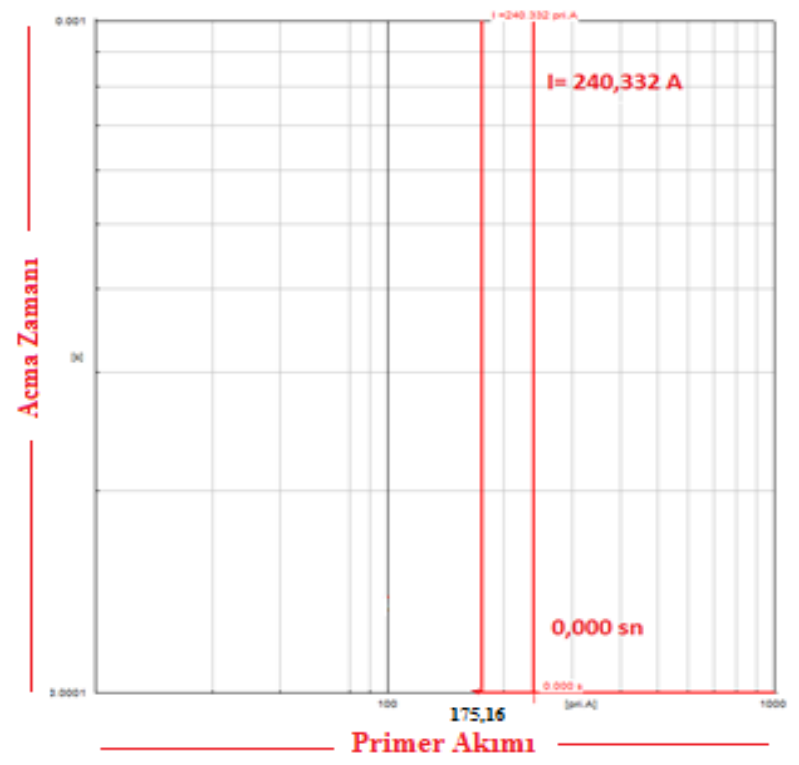

Şekil 10. Güç sistemi modelinde oluşturulan dahili arızaya diferansiyel rölenin tepkisi diferansiyel koruma rölesinin bu arızalara tepkisi detaylı şekilde incelenebilir. Bu bölümde 2 farklı arıza senaryosu oluşturularak oluşabilecek problemler analiz edilmiștir. Bu 2 farklı arıza senaryosunda 3 faz arıza akımı durumu incelenmiştir.

\subsubsection{Senaryo 1}

$\mathrm{Bu}$ senaryoda güç transformatörünün primer ve sekonder tarafındaki akım trafoları arasında kalan bölgede (Şekil 1'de A noktasındaki arıza gibi) bir 3 faz arızası oluşturulmuştur. $\mathrm{Bu}$ arıza akımı güç transformatörünün sekonder tarafından 240 A $\left(240 / \frac{1000}{5}\right)$ olarak güç sistemine uygulansın. Bu durumda güç transformatörünün eşitlik 2 ve 4 'de hesaplanan sınır değerlerinden büyük olacağı için diferansiyel koruma rölesi keserek, transformatörü koruyacaktır. $\mathrm{Bu}$ arızayı bu güç transformatörünü koruyan diferansiyel koruma rölesi, 0 sn.'de görerek açma sinyali oluşturur. Bu durum diferansiyel rölenin, açma diyagramında Şekil $10^{\prime}$ da görüldüğü gibi olur.

Şekil 10'da DigSilent V.15.1.6'da diferansiyel röle karakteristiğinde primer akımına (x ekseni) ne kadar zamanda diferansiyel rölenin açma ürettiği (y ekseni) gösterilmektedir.

\subsubsection{Senaryo 2}

$\mathrm{Bu}$ senaryoda güç transformatörünün primer ve sekonder tarafındaki akım trafoları dışında kalan bölgede (Şekil 1'de B noktasındaki arıza gibi) bir 3 faz arızası oluşturulsun. $\mathrm{Bu}$ arızada röle kesmeyecektir (koruma bölgesi dişında olduğundan). Bu durum Şekil 11'de gösterildiği gibidir. Şekil 11'de verilen 3 faz harici arıza akımında diferansiyel koruma rölesinin devreye girmediği görülmektedir.

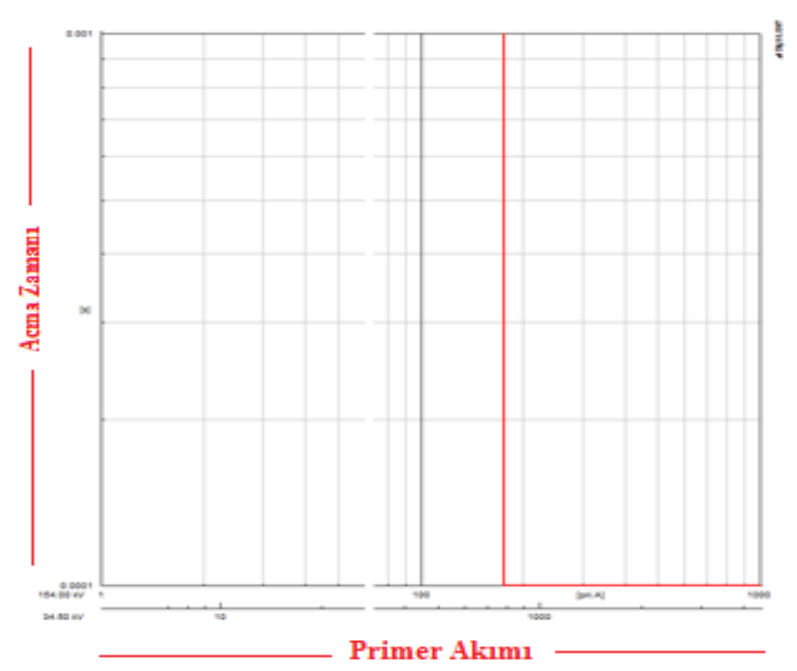

Şekil 11. Güç sistemi modelinde oluşturulan harici arızaya diferansiyel rölenin tepkisi 
Senaryo 1 ve 2 de oluşturulan arızalara, diferansiyel röle istenilen şekilde tepki göstermiştir. $\mathrm{Bu}$ durumda tasarlanan diferansiyel koruma rölesi ile istenilen koruma koordinasyonu sağlanmıștır.

\section{Tartışma ve Sonuç}

Enerji sürekliliği, güç sistemlerinde iyi bir koruma koordinasyonu ile sağlanır. Bu çalıșmada; bir güç transformatörünün diferansiyel koruma röleleri ile korunması konusu irdelenmiștir. Çalışmanın modelleme bölümünde hazır üniteler ile temel bir diferansiyel koruma rölesi tasarlanmıştır. Daha sonra diferansiyel koruma rölesinin ayar değerleri hesaplanmıştır. Güç transformatörü ve diferansiyel koruma rölesinin modellenmesi yapıldıktan sonra, güç sistemi üzerinde çeşitli arıza durumları için 2 arıza senaryosu oluşturulmuş ve diferansiyel rölesinin her arıza için verdiği tepki analiz edilmiştir. Çalışma, sanal modelde oluşturulan arıza senaryoları ile yapılarak, gerçek güç sisteminde risk oluşturabilecek durumlar denenmiş ve risk alınmadan röle ayarlarının bulunması sağlanmıştır.

Bu çalışmadaki gibi güç sistemlerinde modellemeler yaparak, gerçek sistemde risk almadan uygun koruma koordinasyonu ayarları bulunabilir.

\section{Kaynakça}

[1] Rafa, A. H. 2017. Digital differential relay for electrical power transformer. Journal of Engineering Research (University of Tripoli, Libya) 23 (2017): 1.

[2] Guzman, A., Zocholl, Z., Benmouyal, G., and Altuve H.J. 2001. A current-based solution for transformer differential protection. IEEE Transactions on power delivery, Vol.16, Oct. 2001, pp. 485 -491.

[3] Serrican, C.A. 2007. Petkim Petrokimya Aliğa Tesisinin elektrik sisteminin yük akıșı ve kısa devre hesapları. İstanbul Teknik Üniversitesi, Fen Bilimleri Enstitüsü, Yüksek Lisans Tezi, 112s, İstanbul.

[4] Türen, M. 2005. Hall etkili dönüștürücü kullanan diferansiyel rölenin transformatör korumasında kullanılması. Gazi Üniversitesi, Fen Bilimleri Enstitüsü, Yüksek Lisans Tezi, 201s, Ankara.

[5] Perdahçı, C., Can, İ. H. 2011. Güvenirlik Analizi için Digital Röle Koordinasyonu. IV. Emo Enerji Verimliliği ve Kalitesi Sempozyumu, 12-13 Mayıs, Kocaeli, 223-227.
[6] Gençaydın, E. 2006. Enerji iletim hatlarının nümerik mesafe röleleri ile korunması. Yıldız Teknik Üniversitesi, Fen Bilimleri Enstitüsü, Yüksek Lisans Tezi, 306s, İstanbul.

[7] Nuroğlu, F. M. 2011. Dağıtılmış üretim içeren dağıtım şebekelerinde merkezi koordinasyon rölesi tasarımı. Kocaeli Üniversitesi, Fen Bilimleri Enstitüsü, Doktora Tezi. İzmit.

[8] Muangchareon, S., Ngaopitakkul, A., Bunjongjit, S., Leelajindakrairerk, M., Pothisarn, C., Nawikavatan, A. 2013. Study of Coordination between protective devices comprising distributed generation in distribution system. Energy and Engineering, pp. 584-588.

[9] Kezunovic, M and Guo, Y. 2000. Modeling and simulation of the power transformer faults and related protective relay behavior. IEEE Transactions on Power Delivery, 15(1), 44-50.

[10] Phadke, A. G., Thorp, J. S. 1983. A new computer-based flux-restrained current differential relay for power transformer protection. IEEE Transactions on Power Apparatus and Systems, (11), 3624-3629.

[11] Aktaibi, A., Rahman, M. A. 2011. A software design technique for differential protection of power transformers. In Electric Machines \& Drives Conference (IEMDC), 2011 IEEE International pp. 1456-1461.

[12] Kara, B., Özveren, F., \& Usta, Ö. 2017. Aktif Dağıtım Şebekelerinin Diferansiyel Röle İle Korunması Protection of Active Distribution Systems Using Differential Relay, Elektrik Elektronik Mühendisliği Kongresi.

[13] İlhami, A. 2002. Elektrik şebekelerinde sekonder rölelerin bilgisayar ortamında gerçekleştirilmesi. Fırat Üniversitesi, Fen Bilimleri Enstitüsü, Yüksek Lisans Tezi, 69s, Elazı̆̆.

[14] Pınar, M. 1985. Elektrik sistemlerinde koruma, röleler ve röle koordinasyonu. Marmara Üniversitesi, Yüksek Lisans Tezi, , İstanbul.

[15] SIPROTEC Diferansiyel Koruma Rölesi 7UT612 357s.https://www.downloads.siemens.com/d ownload-center/download?DLA06_1667 (Erişim Tarihi: 21.01.2017).

[16] Elektrik Şebeke Yönetmeliği, 2017., http://www.epdk.org.tr/TR/DokumanDetay/E lektrik/Mevzuat/Yonetmelikler/Sebeke, (son erişim tarihi 11.08.2017). 